\title{
S100A8 and S100A9 in experimental osteoarthritis
}

\author{
Hala Zreiqat ${ }^{1{ }^{*}}$, Daniele Belluoccio ${ }^{2+}$, Margaret M Smith ${ }^{3}$, Richard Wilson², Lynn A Rowley ${ }^{2}$, Katie Jones ${ }^{1}$, \\ Yogambha Ramaswamy ${ }^{1}$, Thomas Vogl ${ }^{4}$, Johannes Roth4, John F Bateman², Christopher B Little ${ }^{3}$
}

\begin{abstract}
Introduction: The objective was to evaluate the changes in S100A8 S100A9, and their complex (S100A8/S100A9) in cartilage during the onset of osteoarthritis (OA) as opposed to inflammatory arthritis.

Methods: S100A8 and S100A9 protein localization were determined in antigen-induced inflammatory arthritis in mice, mouse femoral head cartilage explants stimulated with interleukin-1 (IL-1), and in surgically-induced OA in mice. Microarray expression profiling of all S100 proteins in cartilage was evaluated at different times after initiation of degradation in femoral head explant cultures stimulated with IL-1 and surgically-induced OA. The effect of S100A8, S100A9 or the complex on the expression of aggrecan (Acan), collagen II (Col2a1), disintegrin and metalloproteases with thrombospondin motifs (Adamts1, Adamts 4 \&Adamts 5), matrix metalloproteases (Mmp1, Mmp3, Mmp13 \&Mmp14) and tissue inhibitors of metalloproteinases (Timp1, Timp2 \&Timp3), by primary adult ovine articular chondrocytes was determined using real time quantitative reverse transcription polymerase chain reaction (qRT-PCR).
\end{abstract}

Results: Stimulation with IL-1 increased chondrocyte S100a8 and S100a9 mRNA and protein levels. There was increased chondrocyte mRNA expression of \$100a8 and \$100a9 in early but not late mouse OA. However, loss of the S100A8 staining in chondrocytes occurred as mouse OA progressed, in contrast to the positive reactivity for both S100A8 and S100A9 in chondrocytes in inflammatory arthritis in mice. Homodimeric S100A8 and S100A9, but not the heterodimeric complex, significantly upregulated chondrocyte Adamts1, Adamts4 and Adamts 5, Mmp1, Mmp3 and Mmp13 gene expression, while collagen II and aggrecan mRNAs were significantly decreased.

Conclusions: Chondrocyte derived S100A8 and S100A9 may have a sustained role in cartilage degradation in inflammatory arthritis. In contrast, while these proteins may have a role in initiating early cartilage degradation in OA by upregulating MMPs and aggrecanases, their reduced expression in late stages of OA suggests they do not have an ongoing role in cartilage degradation in this non-inflammatory arthropathy.

\section{Introduction}

S100 proteins are low molecular weight (9 to $14 \mathrm{kDa}$ ) intracellular calcium-binding proteins that control key cellular pathways including regulation of the cytoskeleton [1], cell migration and adhesion [2], and host oxidative defense [3,4]. Some S100 proteins have also been demonstrated to have important extracellular pro-inflammatory effects and cytokine-like activities in addition to their intracellular functions. When released from cells,

\footnotetext{
* Correspondence: hzreiqat@usyd.edu.au

+ Contributed equally

'Tissue Engineering and Biomaterials Research Unit, School of AMME J07, Faculty of Engineering, Bosch Institute, University of Sydney, Corner of Shepherd and Cleavland Street, New South Wales 2006, Australia
}

S100A8, S100A9, S100A11, and S100A12 act as unconventional inflammatory cytokines $[5,6]$. Therefore, not only the expression of these proteins by cells, but also their release into the extracellular environment may have important implications on their activity in a given tissue.

S100A8 and S100A9 are found intracellularly in granulocytes, monocytes, and early differentiation stages of macrophages $[7,8]$. A clear increase and role for S100A8 and S100A9 in the synovium and macrophages in inflammatory arthritis has been established $[9,10]$. Extracellular S100A8 is considered a pro-inflammatory molecule because of its effect on cytokine synthesis [11] and upregulation of destructive matrix metalloproteinases (MMP) and disintegrin and metalloproteases with 
thrombospondin motifs (ADAMTS) enzymes by macrophages $[10,12]$. In contrast, S100A9 alone was previously shown not to activate phagocytes and, when it forms a complex with S100A8, to decrease the activity of this S100 protein [11]. Chondrocytes have also been shown to express S100A8 and S100A9 [13] and their upregulation following stimulation with IL-1 and oncostatin-M, suggested a possible role in cartilage repair or inflammation-induced degradation [14]. Recently, increased S100A8 and S100A9 staining of chondrocytes in inflammatory arthropathies in mice and humans was reported [9]. This same study also demonstrated that extracellular S100A8 stimulated expression and activity of various matrix-degrading metalloproteinases by a chondrocyte cell line, and aggrecanolysis in mouse patella explant cultures [9]. These results suggested that in inflammatory arthritis, extracellular S100A8 secreted from inflammatory cells or the chondrocytes themselves may be an important mediator of cartilage matrix degradation.

In contrast to the significant role of infiltrating inflammatory cells and synovial pannus in rheumatoid arthritis (RA), cartilage breakdown in osteoarthritis (OA) is driven primarily by the chondrocytes. Although considered to be a non-inflammatory arthropathy, a role for chondrocyte-derived cytokines in maintaining elevated proteolysis of aggrecan and collagen in end-stage human OA cartilage has been demonstrated [15]. To date, however, the changes in S100A8 and S100A9 expression and protein localization and the potential role of these two proteins in cartilage destruction during the onset and progression of OA as opposed to inflammatory arthropathies has not been investigated. Furthermore, although it has been shown that S100A8 can induce catabolic enzymes expression in chondrocyte cell lines [9], no previous studies have established whether S100A8 has a similar effect in primary adult articular chondrocytes or if S100A9 or the S100A8/A9 complex has a similar effect. We investigated the immunolocalization of S100A8 and S100A9 in sections of antigen-induced arthritis (AIA); the effect of IL-1 $\alpha$ on S100a 8 and S100a9 expression and immunolocalization in mouse cartilage explants in vitro; the in vivo expression and immunolocalization of S100A8 and S100A9 in cartilage during progressive cartilage destruction in an OA compared with an inflammatory arthritis model in mice; and the effect of S100A8 and S100A9 on the expression by primary adult ovine articular chondrocytes of key extracellular matrix molecules, matrix degrading enzymes, and their inhibitors.

\section{Materials and methods}

\section{Mouse osteoarthritis model}

All animal experimentation was conducted with approval from the Royal North Shore Hospital Animal
Care and Ethics Committee (protocols 0051-005A and 0506-019A). OA was induced in 10-week-old male C57BL6 mice by medial meniscal destabilization (MMD) of the right knee [16]. Joints with no surgery or subjected to sham-operation (exposure of the medial menisco-tibial ligament but no transection) were used as controls. Animals were sacrificed at 2, 4, 8 and 16 weeks after surgery ( $n=3$ per time point) for histology and immunohistology.

Additional 10 week-old C57BL6 male mice underwent bilateral surgery with the right knee undergoing MMD while the left knee underwent a sham-operation. Animals were sacrificed at one, two, and six weeks after surgery ( $\mathrm{n}=7$ per time point). The joints were dissected to expose the articular cartilage, tibial epiphyses were isolated and placed in RNA later containing 20\% EDTA, decalcified at $4^{\circ} \mathrm{C}$ for 72 hours and then embedded in optimal cutting temperature (OCT) compound and stored at $-80^{\circ} \mathrm{C}$. Serial $7 \mu \mathrm{m}$ coronal cryo-sections were fixed in ethanol, air-dried, and non-calcified medial tibial plateau articular cartilage from previously assigned areas of cartilage fibrillation and loss of toluidine blue staining were microdissected and isolated using a Veritas microdissection system (Molecular Devices, Sunnyvale, CA, USA).

\section{Mouse cartilage isolation and culture}

Femoral head cartilage was isolated from 24-day-old C57B6 wild type mice and cultured for two or four days in serum-free medium with or without $10 \mathrm{ng} / \mathrm{ml}$ recombinant human IL-I $\alpha$ (PeproTech, London, UK [17]. In four-day cultures the media was changed after two days. At termination, femoral heads were either stored at $-20^{\circ}$ $\mathrm{C}$ in RNA later (Ambion, Austin TX, USA) prior to RNA extraction or embedded in OCT and stored at $-80^{\circ}$ $\mathrm{C}$ prior to immunostaining.

\section{Chondrocyte isolation and culture}

Chondrocytes from four-year-old ovine knee articular cartilage were isolated by sequential pronase and collagenase digestion and grown to confluence in serumcontaining media [18]. Cells were incubated overnight in serum-free medium prior to stimulation for 24 hours with serum-free medium containing $10^{-7}$ or $10^{-8} \mathrm{M}$ recombinant human S100A8, S100A9, or the complex of both ( $\mathrm{n}=6$ replicates/treatment). Recombinant human S100A8, S100A9, or heterocomplex with no contaminating lipopolysaccharise (LPS) were expressed and purified as described $[13,19,20]$.

\section{RNA extraction}

At the termination of culture, ovine chondrocytes were washed with PBS, and then lysed with TRIzol (Invitrogen Life Technologies, Mulgrave, Victoria, Australia). 
Mouse femoral heads were pulverized using a liquid nitrogen-cooled tissue mill. Pulverised femoral heads and micro-dissected cartilage from frozen sections of sham or MMD-induced OA joints were extracted with TRIzol. Total cellular RNA in TRIzol extracts was isolated from all samples by RNeasy kit (Qiagen, Doncaster, Victoria, Australia) including an on-column DNase I (Qiagen, Doncaster, Victoria, Australia) digestion. RNA was quantified using Sybrgreen (Molecular Probes, USA) with 18S/28S rRNA as a standard (Sigma-Aldrich, Castle Hill, NSW, Australia). Three femoral heads were pooled to generate a representative RNA sample for each in vitro treatment and were analysed by microarray expression profiling. Micro-dissected cartilage from three separate joints was pooled to account for biological variability, and provide a representative sample of sham or MMD cartilage RNA at each time point for microarray analysis. The RNA from the remaining four sham and MMD joints were analysed separately using quantitative RT-PCR (qRT-PCR) for S100a8 and S100a9 to verify the results from the microarray analysis.

\section{Ovine chondrocyte quantitative reverse transcription polymerase chain reaction}

Changes in mRNA expression in cultured primary ovine chondrocytes were quantified using real-time qRT-PCR as previously described [21]. Reverse transcription (RT) reactions were undertaken with $1 \mu \mathrm{g}$ total RNA (Omniscript RT kit, Qiagen, Doncaster, Victoria, Australia). All samples underwent RT at the same time to avoid potential variations in experimental conditions. Aliquots of cDNA were amplified by PCR using specific ovine primer sets (Table 1). All PCR reactions generated single products with confirmed sequences (SUPAMAC, Sydney University, NSW, Australia). The differentiated phenotype of control cultures of primary ovine chondrocytes in monolayer was confirmed by examining gene expression relative to Gapdh. However, all 'housekeeping' genes evaluated (Gapdh, Actb, Hprt, ubiquitin) showed differential regulation by $\mathrm{S} 100$ proteins (data not shown). Therefore, to evaluate the changes induced by S100A8, S100A9, or the heterocomplex, gene expression in all cultures including controls was subsequently corrected for total RNA [22] and the effect of added S100 proteins expressed as fold change from control cultures.

\section{Mouse cartilage RNA amplification, microarray hybridization and qRT-PCR}

To quantify changes in all S100 mRNA in cultured mouse femoral heads and micro-dissected tibial cartilage from the OA model, linear amplification in one or two rounds, respectively, was performed using the MessageAmp kit

Table 1 Ovine-specific real time PCR primer pair sequences, annealing temperatures and product size

\begin{tabular}{|c|c|c|c|c|}
\hline Target gene & Sequence & Anneal temp $\left({ }^{\circ} \mathrm{C}\right)$ & Product size (bp) & $\begin{array}{l}\text { Accession number or } \\
\text { reference if published }\end{array}$ \\
\hline Acan & $\begin{array}{l}\text { F - TCA CCA TCC CCT GCT ACT TCA TC } \\
R \text { - TCT CCT TGG AAA TGC GGC TC }\end{array}$ & 58 & 105 & {$[21]$} \\
\hline Adamts1 & $\begin{array}{l}\text { F - CCA ACT GGA GCC ACA AAC ATT G } \\
R \text { - GGA CAG AGT GAA GTC GCC ATT C }\end{array}$ & 55 & 126 & [GenBank: XM_589626] \\
\hline Adamts4 & $\begin{array}{l}\text { F - AAC TCG AAG CAA TGC ACT GGT } \\
R \text { - TGC CCG AAG CCA TTG TCT A }\end{array}$ & 60 & 149 & [44] \\
\hline Adamts5 & $\begin{array}{l}F \text { - GCA TTG ACG CAT CCA AAC CC } \\
R \text { - CGT GGT AGG TCC AGC AAA CAG TTA C }\end{array}$ & 55 & 97 & [21] \\
\hline Col2al & $\begin{array}{l}\text { F - TGA CCT GAC GCC CAT TCA TC } \\
\mathrm{R}-\text { TTT CCT GTC TCT GCC TTG ACC C }\end{array}$ & 55 & 154 & [GenBank: X02420] \\
\hline Mmp1 & $\begin{array}{l}\text { F - CAT TCT ACT GAC ATT GGG GCT CTG } \\
\text { R - TGA GTG GGA TIT TGG GAA GGT C }\end{array}$ & 55 & 122 & [GenBank: AF267156] \\
\hline Mmp3 & $\begin{array}{l}\text { F - TCC CCC AGT TTC CCC TAA TG } \\
R \text { - GAT TTC TCC CCT CAG TGT GCT G }\end{array}$ & 58 & 124 & [GenBank: AF135232] \\
\hline Mmp13 & $\begin{array}{l}\text { F - GGT GAC AGG CAG ACT TGA TGA TAA C } \\
\text { R - ATT TGG TCC AGG AGG GAA AGC G }\end{array}$ & 58 & 349 & {$[21]$} \\
\hline Mmp14 & R - CCC AGT GCT TGT CTC CTT TGA AG & 56 & 126 & [GenBank: AF267160] \\
\hline Timp1 & $\begin{array}{l}\text { F - GGT TCA GTG CCT TGA GAG ATG C } \\
\text { R - GGG ATA GAT GAG CAG GGA AAC AC }\end{array}$ & 57 & 265 & [GenBank: S67450] \\
\hline Timp2 & $\begin{array}{l}\text { F - ACT CTG GCA ACG ACA TCT ACG G } \\
\text { R - TCT TCT TCT GGG TGG CAC TCA G }\end{array}$ & 57 & 261 & [GenBank: M32303] \\
\hline Timp3 & $\begin{array}{l}\text { F - CTT CCT TTG CCC TTC TCT ACC C } \\
\text { R - TCT GGT CAA CCC AAG CAT CG }\end{array}$ & 57 & 286 & [GenBank: NM_174473] \\
\hline Gapdh & $\begin{array}{l}\text { F - CCT GGA GAA ACC TGC CAA GTA TG } \\
\text { R - GGT AGA AGA GTG AGT GTC GCT GTT G }\end{array}$ & 58 & 139 & [GenBank: U94889] \\
\hline
\end{tabular}

Acan = aggrecan; Adamts = a disintegrin and metalloproteinase with thrombospondin motifs; F = forward primer; Gapdh = glyceraldehyde 3-phosphate dehydrogenase; $M m p=$ matrix metalloproteinase; $\mathrm{R}=$ reverse primer; Timp = tissue inhibitor of metalloproteinases. 
(Ambion, Austin TX, USA) following the manufacturers guidelines. Aminoallyl-modified UTP was incorporated and then labelled with reactive fluorophors $\mathrm{Cy} 3$ or $\mathrm{Cy} 5$ (GE Healthcare, Rydalmere, NSW, Australia). Duplicate microarrays (Cy3/Cy5 dye-swap with replicate RNA samples) were performed for in vitro treatment (i.e. control versus IL-1 at each time point), and sham versus MMD (at one, two and six weeks). Labelled RNA was hybridized to $44 \mathrm{k}$ whole genome oligo microarrays (G4122A, Agilent Technologies, Forest Hill, Victoria, Australia). The arrays were scanned on an Axon 4000B scanner and features extracted with GenePix Pro 4.1 software (Molecular Devices, Sunnyvale, CA, USA). Raw data was processed using a print-tip Loess normalization [23] using limmaGUI software [24]. Mean log2-transformed expression ratios and B-statistic values (log posterior odds ratio [23] were calculated for all direct comparisons [25]. Data is plotted as the average fold-change compared with control for femoral head culture experiments, or average foldchange with MMD compared with sham surgery at each time point. The changes in S100a8 and S100a9 mRNA expression in micro-dissected mouse tibial cartilage following MMD were validated by qRT-PCR in four separate animals at each time point, and the median fold change in MMD compared with sham-operated joints was calculated. These analyses were performed as previously described [26] using mouse-specific primer pairs (S100a8 forward - TGCGATGGTGATAAAAGTGG, reverse GGCCAGAAGCTCTGCTACTC; S100a9 forward CACAGTTGGCAACCTTTATG, reverse - CAGCTGATTGTCCTGGTTTG), and the expression of S100a8 and $S 100 a 9$ were normalized using the geometric mean expression of two housekeeping genes [27], Atp5b (forward - GGCTGATAAGCTGGCAGAAG, reverse - GGAGAGATCAGTTGCAGTGCT), and Rpl10 (forward TTGAAGACATGGTTGCTGAGA, reverse - AGGACCACGATTGGGGATA). These two housekeeper genes were shown by microarray expression profiling to be unchanged during the onset and progression of OA in the MMD mouse model (data not shown).

\section{Immunolocalization of S100A8 and S100A9}

Sections from archival paraffin blocks of male C57BL6 mouse knee joints with either AIA ( 7 and 28 days after induction) or saline injection from a previous study [16] were prepared at the same time as serial sections from the mouse knee joints with surgically-induced OA. Together with frozen sections from femoral head cultures, slides were immunolocalized with polyclonal antibodies to S100A8 and S100A9 (generously provided by Professor Caroline Geczy [13] and Dr. Thomas Vogl $[9,12])$. Immunostaining with the two different S100A8 and S100A9 antibodies gave similar results, and therefore only those obtained using the antibodies supplied by Zreiqat and colleagues [13] are shown. Negative controls included omitting the primary antibody or using an equivalent concentration of rabbit immunoglobulin (Ig) G as a control for nonspecific antibody binding. Images representative of typical immunostaining in mouse knee joints with either OA or AIA are presented. The antibodies to S100A8 did not recognize recombinant S100A9 on western blotting and vice versa (data not shown); the anti-S100A8 and anti-S100A9 polyclonal antibodies did not cross-react with human S100A12, S100B or S100A1 [28,29]. The specificity of immunostaining was further validated by pre-absorption with 10 nmol of the recombinant proteins for one hour at room temperature prior to immunolocalization.

\section{Statistical analysis}

Comparisons of parametric data were undertaken using the unpaired Student's t-test with Benjamini-Hochberg correction for multiple comparisons [30]. Differential expression in microarray analysis was assumed for Bstatistic of 1.0 or more [23].

\section{Results}

S100A8 and S100A9 immunolocalization in antigen induced arthritis

As previously described [16] there is a complete loss of proteoglycan staining in the non-calcified cartilage by seven days post AIA induction (Figure 1). Chondrocytes, particularly in the deep and to a lesser extent the superficial zone of the non-calcified articular cartilage were positive for S100A8, but not S100A9 in control (salineinjected) joints. S100A8 reactivity remained positive in the non-calcified cartilage in AIA joints, either at levels similar to or increased compared with saline-injected (non-inflamed) control joints (Figure 1). This positive chondrocyte S100A8 staining was observed up to 28 days after induction of AIA even though there is significant resolution of the synovial inflammation at this time point [16]. Chondrocytes in the non-calcified articular cartilage became immunopositive for S100A9 at seven days after AIA induction, and remained positive at 28 days (Figure 1). Meniscal fibrochondrocytes showed positive S100A8 and S100A9 immunostaining in AIA joints at all times. Cells in the bone marrow of all joints and inflammatory cells in the synovium (not shown) and joint space (Figure 1, day seven) were also strongly positive for S100A8 and S100A9.

\section{Immunolocalization of S100A8 and S100A9 in mouse OA}

Meniscal destabilization induced a progressive deterioration of the articular cartilage in the medial femoro-tibial joint (Figure 2a) with no evidence of synovial inflammation as previously described [16]. Cartilage damage at two weeks was characterized by a focal loss of 


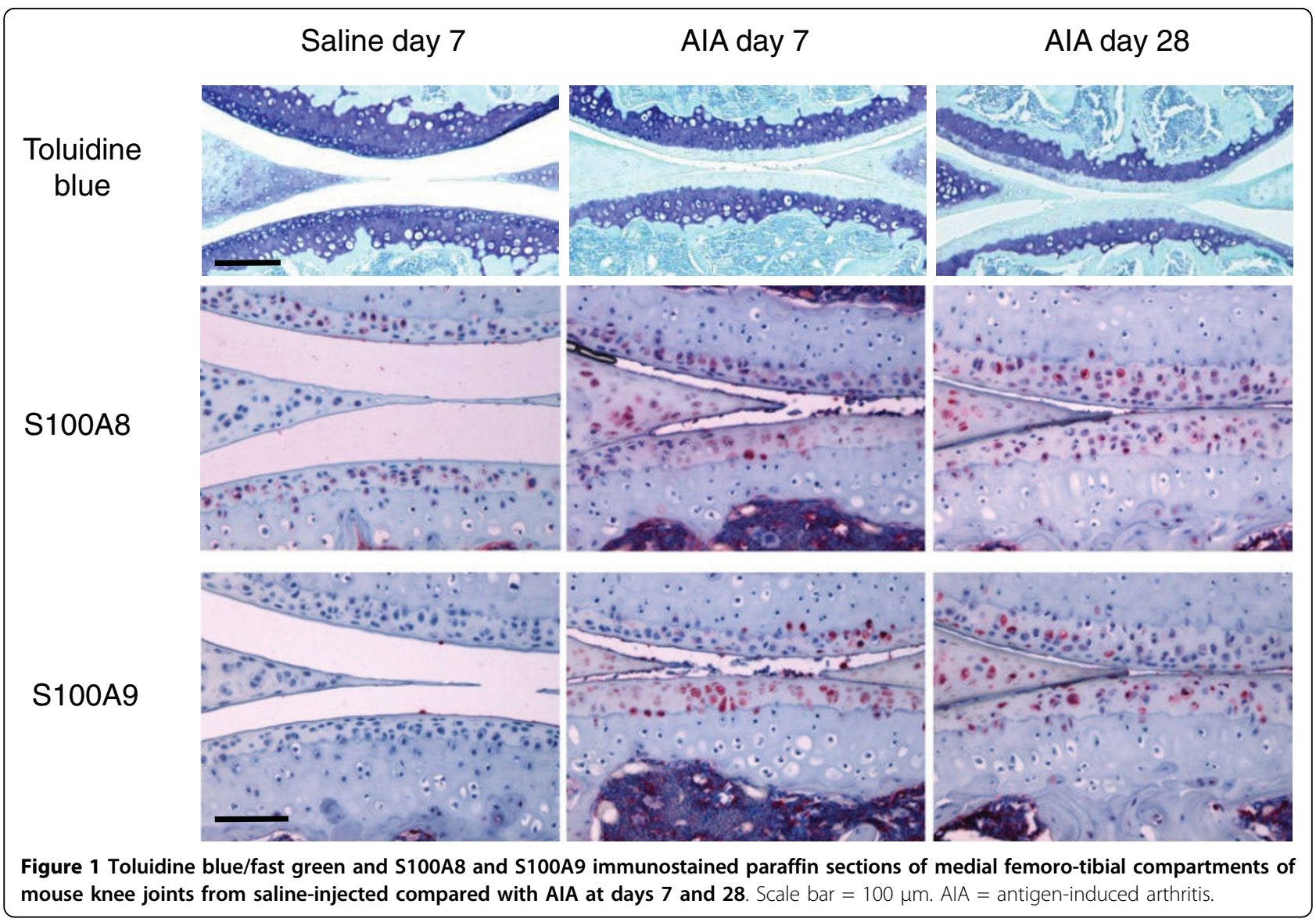

proteoglycan from the non-calcified cartilage in the central weight-bearing region of the tibial plateau but no structural damage. The area of proteoglycan loss expanded with time and at eight weeks was accompanied by evidence of surface fibrillation and some areas of erosion. By 16 weeks there was full thickness erosion of non-calcified cartilage to cover over $50 \%$ of the joint surface.

There was no difference in immunostaining for S100A8 and S100A9 between non-operated and shamoperated joints at any time (results not shown) and therefore only sham-operated results are included (Figure $2 \mathrm{~b}$ ). As described in saline-injected joints above, chondrocytes throughout the non-calcified cartilage in non-operated and sham-operated joints showed positive staining for S100A8 (Figure 2b) but not S100A9 (not shown). In marked contrast to the AIA model, with induction of $\mathrm{OA}$ there was a loss of chondrocyte S100A8 immunoreactivity in the non-calcified cartilage compared with the corresponding sham-operated joint (Figure 2b). The loss of S100A8 chondrocyte staining extended beyond the area of proteoglycan loss defined by decreased toluidine blue staining. Even at late stages of OA with extensive cartilage erosion, chondrocytes in the remaining intact cartilage in the load-bearing region of the joint had reduced or lost S100A8 reactivity (Figure $2 \mathrm{~b}$, week 8 and 16). However, S100A 8 reactivity was still apparent in chondrocytes at the joint margins at all time points, and in the calcified cartilage, bone marrow and bone of developing and mature osteophytes (Figure 3 ). In contrast, chondrocytes showed little positive S100A9 immunostaining in marginal regions in either normal (non-operated or sham-operated) or OA joints, although bone marrow and some osteocytes were positive (Figure 3).

\section{Temporal changes in in vivo expression of $\mathrm{S} 100$ genes in mouse $O A$}

To determine whether the loss of S100A8 immunostaining in cartilage in OA was due to decreased expression, microarray mRNA expression profiling of the S100 protein family was performed [see Additional file 1]. The expression of all S100 genes in chondrocytes in the non-calcified articular cartilage at one, two and six weeks post-induction of OA was determined and results expressed as fold change compared with the sham-operated joints (Figure 4). The expression of a number of S100 mRNAs including S100a5, S100a6, S100a8, 

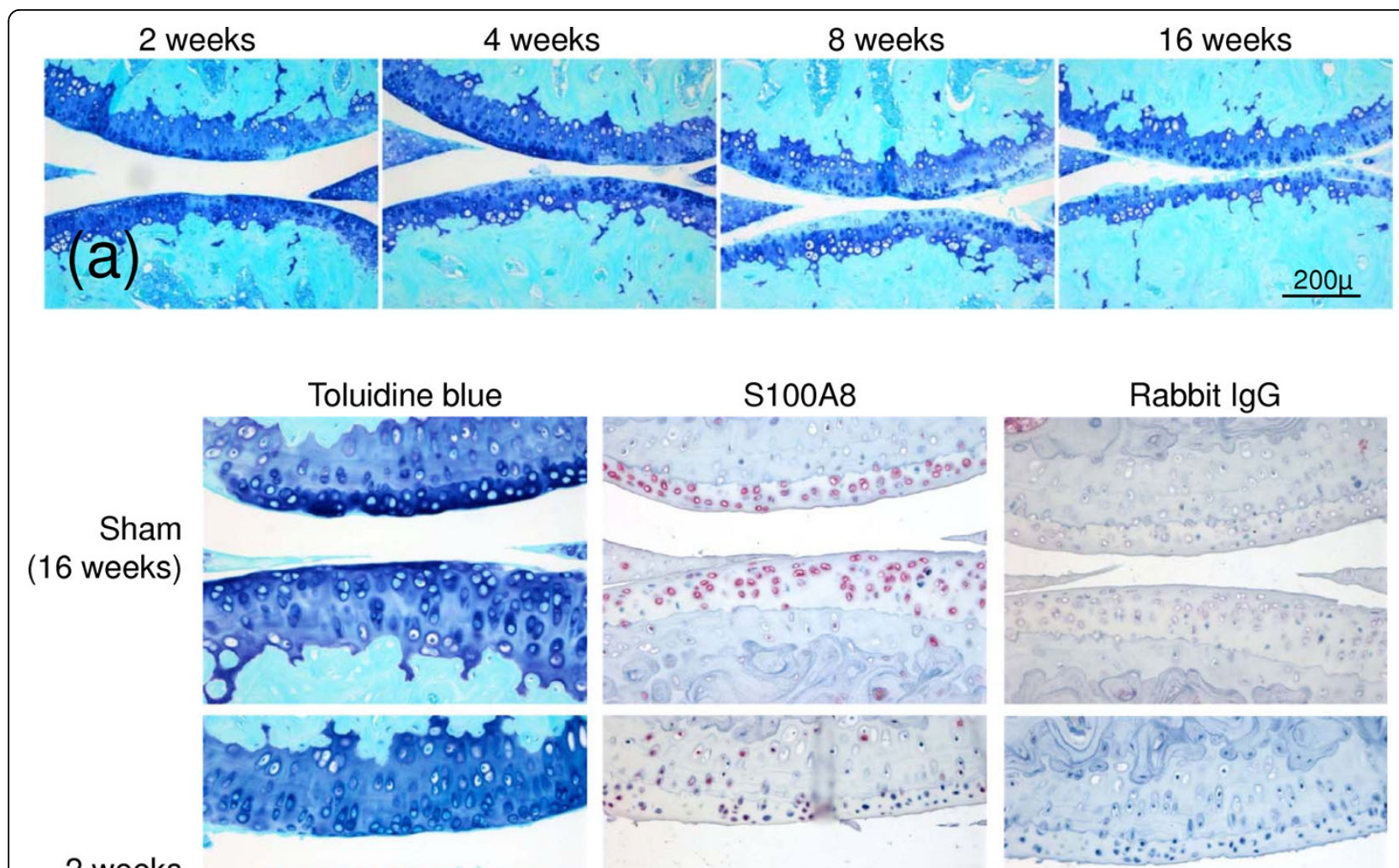

2 weeks
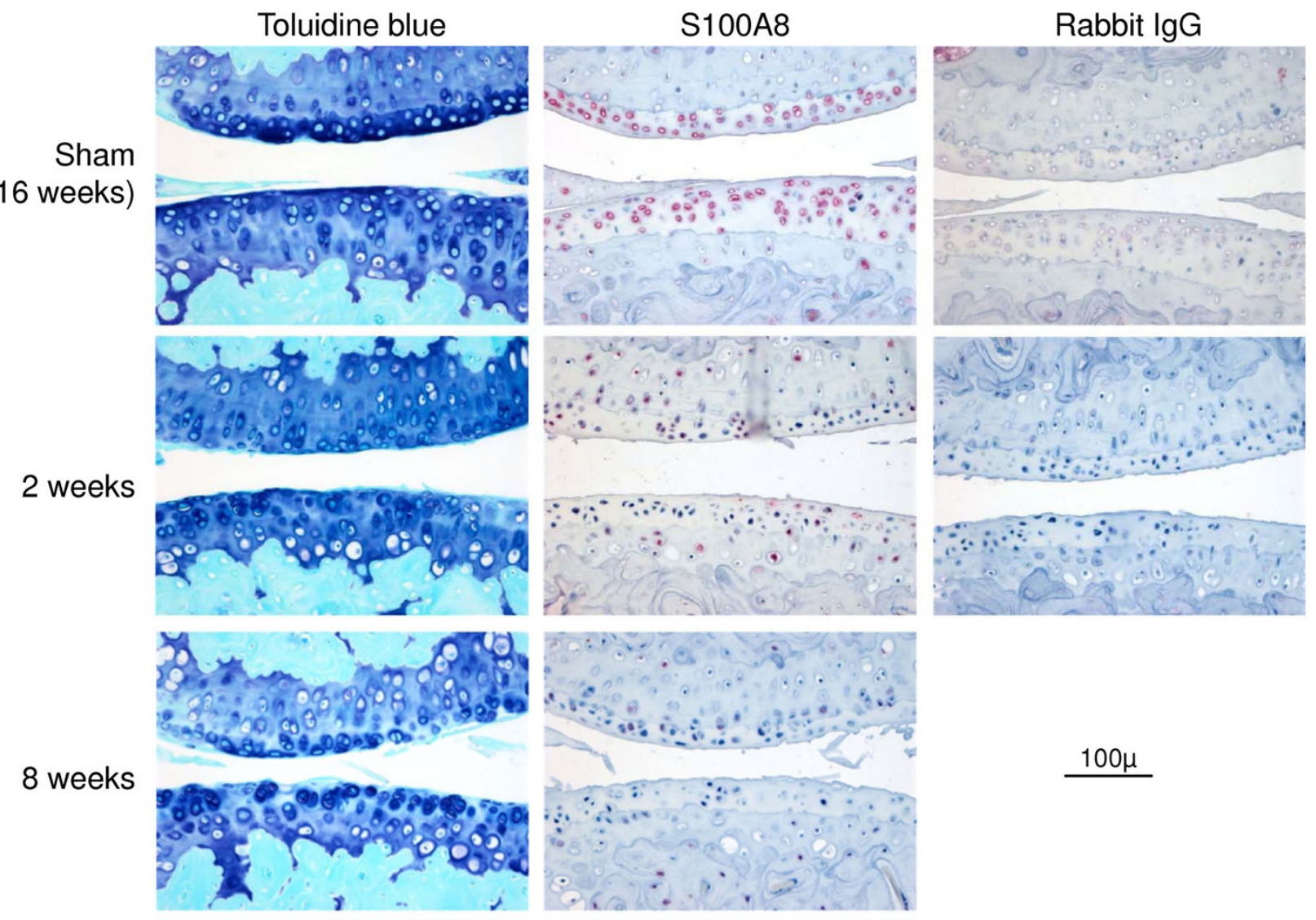

16 weeks
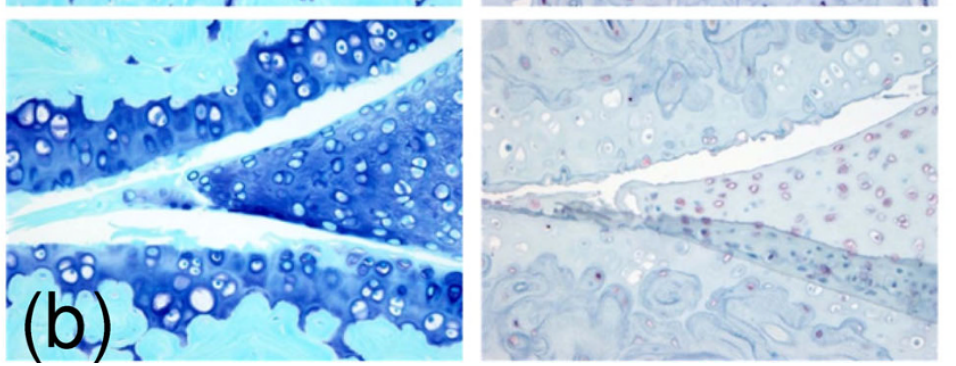

Figure 2 Histopathological examination of osteoarthritic changes in mouse knee (femoro-tibial) joints following medial meniscal destabilization (MMD). (a) Progressive cartilage damage at 2, 4, 8 and 16 weeks following medial meniscal destabilization-induced osteoarthritis (OA) in mouse knee joints. Toluidine blue/fast green stained paraffin sections. Scale bar $=200 \mu m$. (b) Serial sections stained with toluidine blue or with S100A8 immunolocalization in mouse knees at different times following medial meniscal destabilization (MMD) or sham surgery (at 16 weeks). Scale bar $=100 \mu \mathrm{m}$. Negative control sections were immunostained using an equivalent concentration of rabbit lgG. 


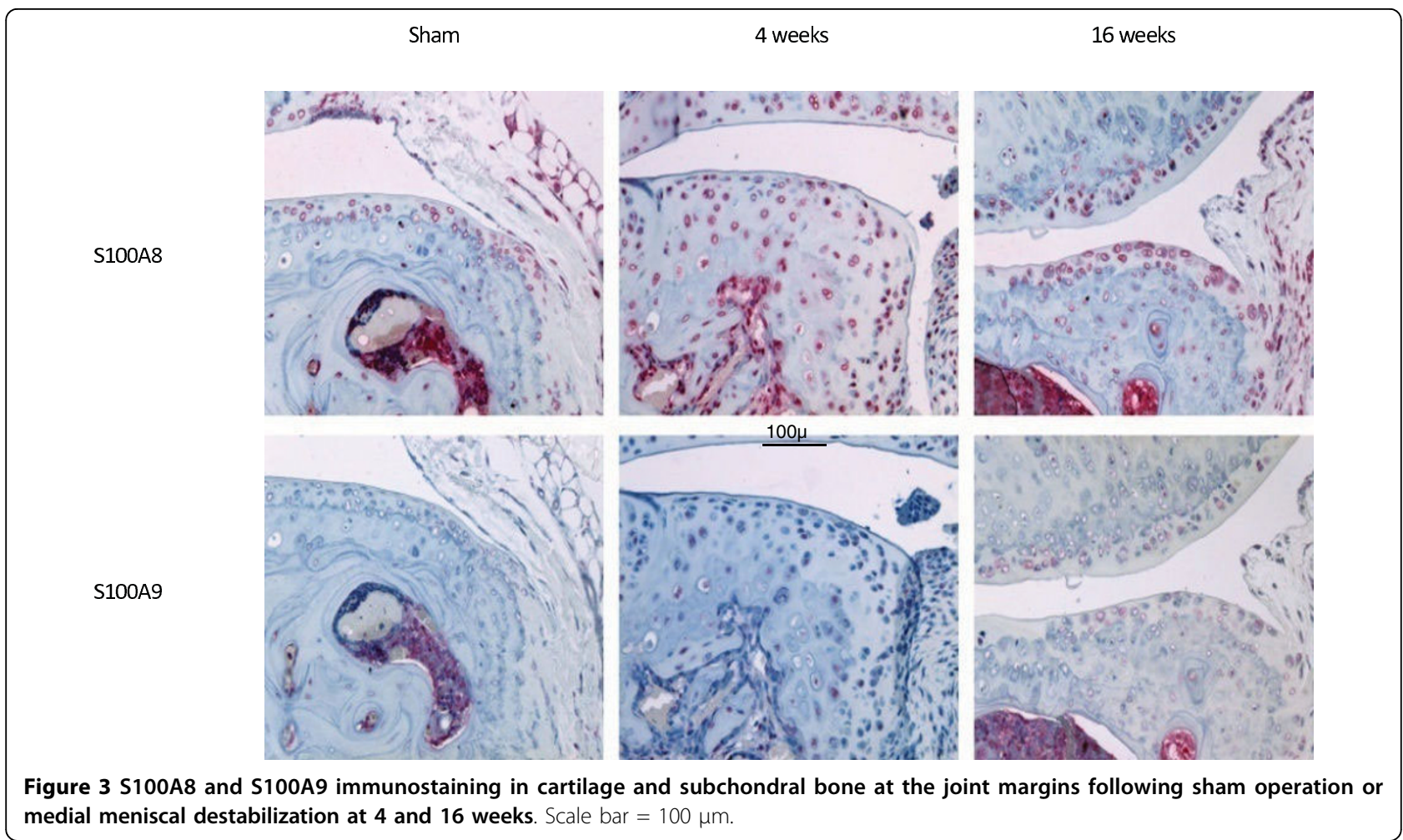

S100a9, S100a11, and S100b was significantly (B-statistic $\geq 1.0$ ) regulated in chondrocytes following surgical induction of OA. The most highly regulated were S100a8 and S100a9, and, unlike other S100 family members, they showed differential regulation with 7- to 14fold upregulation in early (week one and two) stages of $\mathrm{OA}$ and a 7- to 18-fold decrease compared with shamoperated levels in late-stage (week six) disease. The change in S100a8 and S100a9 expression measured using qRT-PCR showed some variability between the individual animals. Nevertheless, three of the four animals at each time point showed the same direction (i.e. increase or decrease) of change, and the median fold change $(n=4)$ had a similar temporal pattern to that observed in microarray analysis: 3.9 - and 11-fold increase in S100a8 and S100a9, respectively, in early OA (two weeks), and a 16- and 25-fold decrease, respectively, in late-stage (six weeks) MMD-induced OA.

\section{In vitro regulation of S100A8 and S100A9 in mouse cartilage}

In light of the distinct temporal change of $S 100$ mRNAs, and particularly S100a 8 and S100a9, in chondrocytes in $\mathrm{OA}$, we investigated the regulation of expression of this family of proteins during IL-1-induced degradation in cartilage explants using microarray expression profiling [see Additional file 2]. In contrast to the changes seen in OA (Figure 4), chondrocyte expression of S100a5,
S100a6, and S100a11 was not regulated by IL-1 in vitro (Figure 5a). S100a8 and S100a9 were both upregulated by IL-1 at day four (10 and 9 fold, respectively) but not day two, while expression of S100a4 was decreased by IL-1 (about seven fold) at both two and four days (Figure 5a). At day 2, S100a8 and S100a9 protein was localized to the chondrocytes in control cultures, although not all cells were positive (Figure $5 \mathrm{~b}$ ). In comparison to the loss of S100A8 immunostaining seen in surgicallyinduced OA (Figure 2b), the number and/or intensity of chondrocyte S100A8 and S100A9 staining was increased in IL-1-stimulated cartilage at day four, particularly in flattened surface zone cells, such that all cells as well as the surface matrix lamina were positively immunostained for both proteins (Figure 5b). Weak staining of calcified cartilage matrix but not chondrocytes or the surface matrix was evident with equivalent concentrations of rabbit IgG even in IL-1-stimulated cultures, and staining was abolished pre-absorption with the recombinant protein (Figure $5 b$ ).

\section{S100A8 and S100A9, but not S100A8/S100A9 complexes regulate chondrocyte gene expression}

We sought to determine whether S100A8, S100A9, and/ or their heterodimeric complex had a similar pro-catabolic effect in primary chondrocytes as previously reported for S100A8 alone in a chondrocyte cell line [9]. We therefore compared mRNA expression of key 
cartilage matrix proteins, enzymes, and their inhibitors in primary adult articular chondrocytes stimulated with physiologically-relevant concentrations of S100A8, S100A9, or their complex. Primary ovine chondrocytes in monolayer culture maintained their anabolic chondrocyte phenotype with relatively high expression relative to Gapdh of aggrecan ( $3.0 \pm 0.6)$, type II collagen $(3.0 \pm 0.4)$, tissue inhibitors of metalloproteinases (Timp)1 (1.4 \pm 0.4$)$, Timp2 (2.3 \pm 0.3$)$, and Timp3 (1.4 $\pm 0.3)$ and generally low catabolic enzyme expression (Adamts $1=0.9 \pm 0.1 ;$ Adamts $4=0.2 \pm 0.1 ;$ Adamts $5=$ $0.4 \pm 0.1 ; M m p 1=0.06 \pm 0.01, M m p 3=0.3 \pm 0.1$; Mmp13 $=0.06 \pm 0.03$ and $M m p 14=1.8 \pm 0.06)$. None of the genes examined were significantly regulated by the heterodimeric S100A8/S100A9 complex (Figure 6). In contrast, both S100A8 and S100A9 homodimers caused a dose-dependent downregulation of chondrocyte aggrecan expression whereas Adamts1, Adamts4, and Adamts5 mRNA levels were all significantly increased (Figure 6). Collagen type II mRNA was significantly decreased by S100A8 or S100A9, while Mmp1, Mmp3, and Mmp13 were dose-dependently upregulated. Timp1 and Timp 3 mRNAs were largely unchanged, while Timp 2 mRNA levels were decreased by S100A 8 and S100A9 (Figure 6). The pattern of most highly upregulated genes by S100A8 and S100A9 $\left(10^{-7} \mathrm{M}\right)$ were similar with, from most to least upregulated, Mmp13 then Mmp1 then Adamts4 then Mmp3 and finally Adamts5.

\section{Discussion}

In this study S100A8 was immunolocalized in chondrocytes in normal murine articular cartilage in vivo, and for the first time we showed that this intracellular S100A8 is lost in OA. This contrasted sharply with the retention or increase of S100A8 immunostaining in chondrocytes in cartilage from inflammatory arthropathies such as AIA. S100A9 protein was not detectable in chondrocytes in the normal non-calcified region of the articular cartilage, and although it increased in inflammatory arthritis, no chondrocyte or cartilage immunostaining was detected in OA. We found that the lack of S100A8 and S100A9 protein localization in chondrocytes early in OA, was not associated with a decrease but rather a significant increase in mRNA expression for both proteins. Although increased chondrocyte mRNA for $S 100 a 8$ and $5100 a 9$ could be induced by IL-1 in vitro, this was associated with an increase in cell and cartilage matrix staining for the two proteins. Together with the distinctly different chondrocyte expression profile of other S100 proteins in IL-1-stimulated compared with OA murine cartilage, this suggests that the early upregulation of S100A8 and S100A9 in surgicallyinduced OA was not due to increased IL-1 activity. Importantly, increased mRNA levels for both S100a8 and S100a9 in early OA was associated with a loss of cellular staining, suggesting that these S100 proteins may be secreted from the cells and act as extracellular signaling molecules. We have now shown that 
(a)

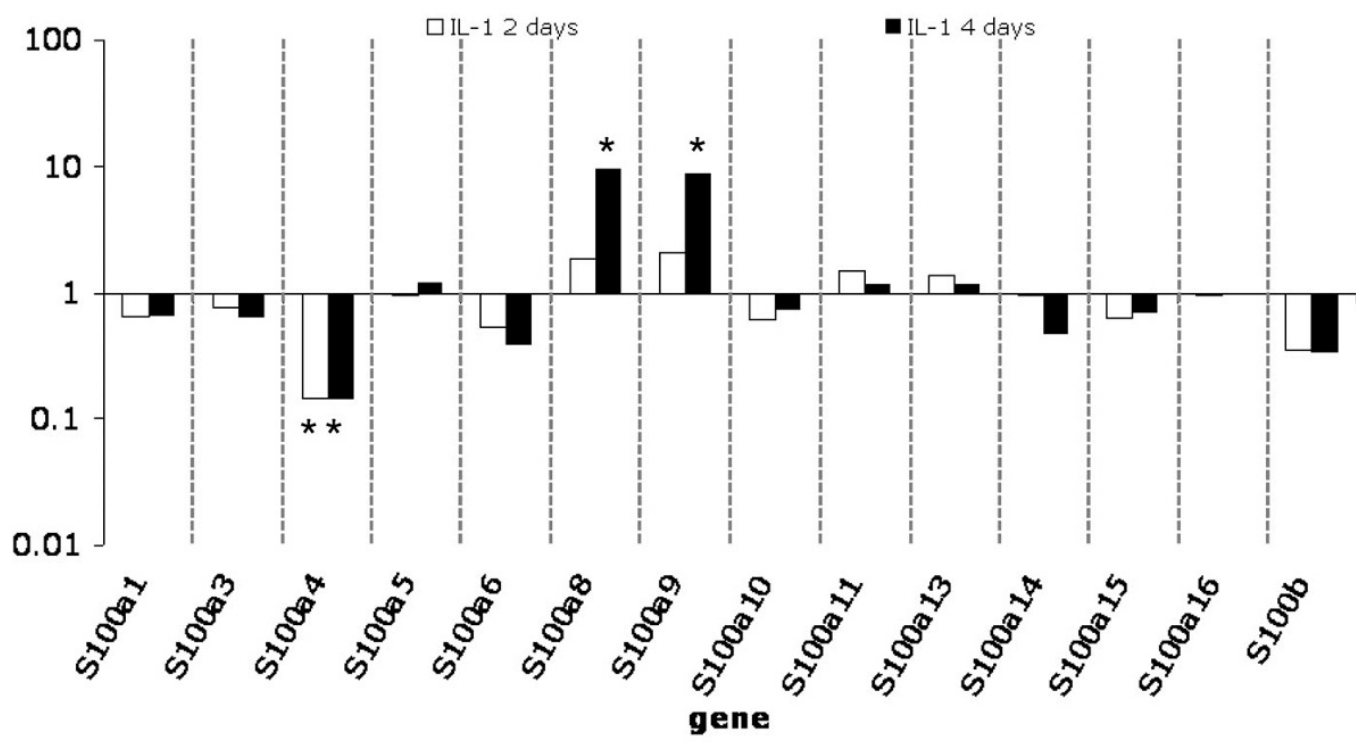

(b)

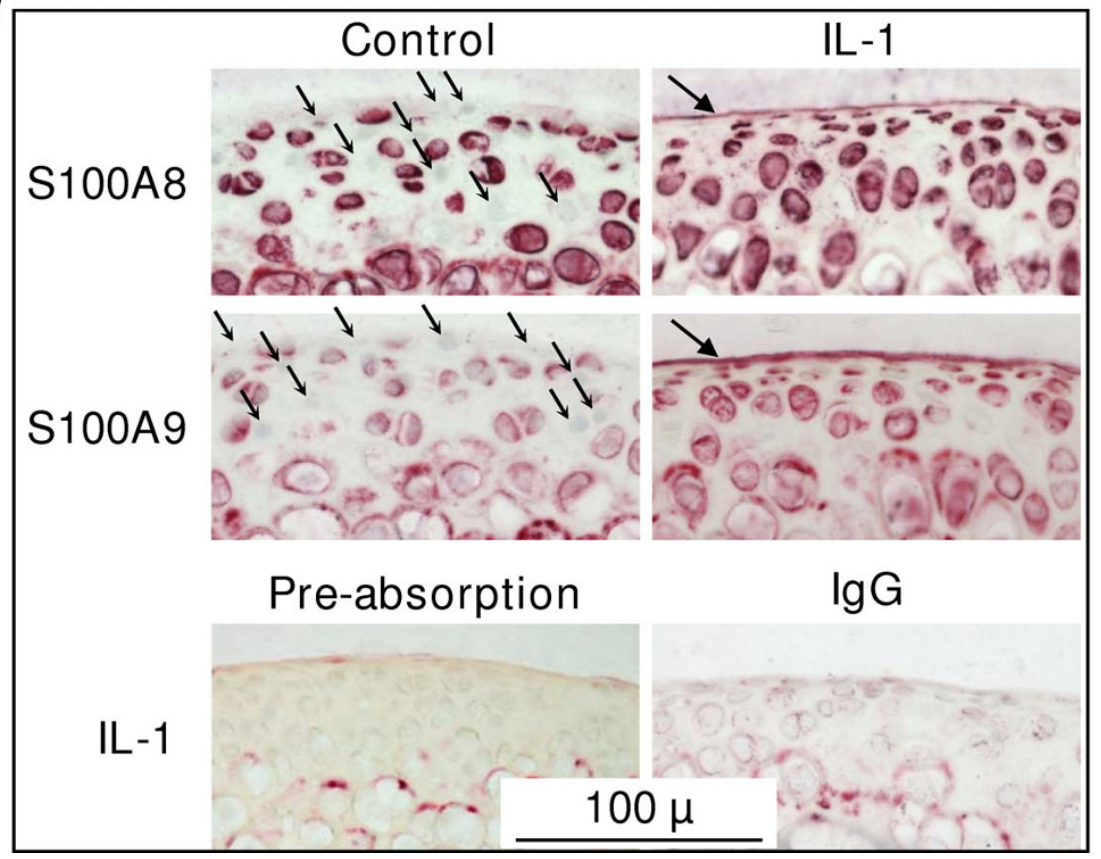

Figure $\mathbf{5}$ Changes in $\mathbf{S 1 0 0}$ proteins in cultured mouse articular cartilage. (a) Fold change in $\$ 100$ gene expression, measured by microarray expression profiling, in mouse femoral head cartilage cultured with or without IL-1 for two or four days compared with control cultures measured by microarray expression profiling (pooled sample from three femoral heads/treatment/time). *B-statistic $\geq 1.0$. (b) S100A8 and S100A9 immunostaining in frozen sections of mouse femoral head articular cartilage following four days of culture with IL-1. Substantial numbers of chondrocytes did not stain with S100A8 and S100A9 in the control cultures (small arrows). In IL-1-stimulated cultures the intensity and proportion of positively stained chondrocytes increased. In addition, the surface matrix lamina stained positive for both S100A8 and S100A9 (large arrows). Negative controls included sections of IL-1-stimulated cartilage incubated with equal concentration of IgG, or localized with antiS100A8 following pre-absorption with recombinant S100A8 protein. Scale bar $=100 \mu \mathrm{m}$. 

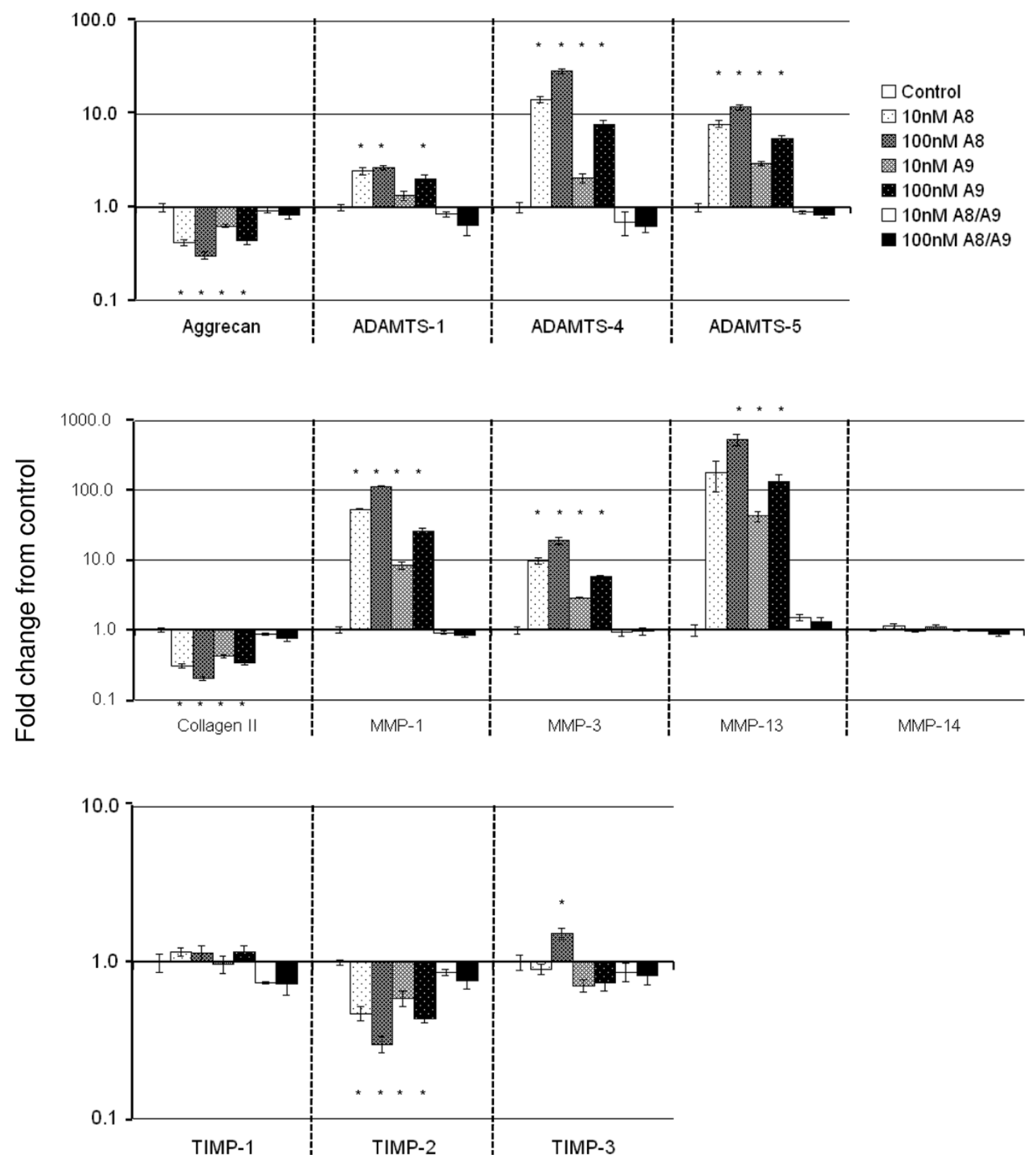

Figure 6 Fold change $( \pm$ SEM) compared with unstimulated cultures in gene expression measured by real-time qRT-PCR in primary ovine chondrocytes cultured for 24 hours in monolayer with 10 or $100 \mathrm{nM} \mathrm{S100A8,} \mathrm{S100A9}$ or S100A8/S100A9 complex. $n=6$ per culture condition. ${ }^{*}=$ significant difference compared with control cultures $(P<0.027)$.

homodimeric S100A9 promotes increased catabolic enzyme and decreased matrix protein gene expression in chondrocytes very similar to that induced by the S100A8 homodimer. In contrast, the heterodimeric complex failed to alter chondrocyte metabolism, suggesting that a dysregulation in expression and/or secretion of the two subunits may play a significant role in their potential bioactivity.

Taken together the above novel findings suggest that the regulation of S100a8 and S100a9 expression and secretion from chondrocytes could play a role in the early stages of cartilage degradation in OA, and highlight the significant differences in the pathogenesis of cartilage destruction in OA versus inflammatory joint diseases. The strong positive chondrocyte staining for both S100A8 and S100A9 observed in AIA in the current study was in accord with previously reported results in this inflammatory arthritis model [9]. However, we found that normal mouse articular chondrocytes were positive for S100A8, the specificity of which was 
confirmed by the lack of staining with equivalent preimmune IgG and pre-absorption of the antibody with recombinant S100A8. This positive S100A8 staining contrasts with a previously reported lack of immunostaining in normal mouse knees [9], but is consistent with positive S100A8 and S100A9 staining in murine and human growth plate chondrocytes [13], and non-stimulated H4 murine chondrocyte cells [9]. The reason for this discrepancy is unclear but may relate to differences in staining sensitivity due to fixation, decalcification, antibodies, and/or immunostaining methods used. Indeed, in frozen sections of mouse femoral head cartilage we could show positive S100A9 as well as S100A8 staining. This different staining pattern in the femoral head cartilage compared with adult joints, may be due to the age of the mice from which the cartilage was obtained, and/or that the tissue was cultured for four days prior to immunostaining. Nevertheless, the results are consistent with active synthesis of both S100A8 and S100A9 proteins by chondrocytes in normal non-calcified articular cartilage. The change in S100A8 immunostaining in surgically-induced mouse OA was restricted to the load-bearing areas of articular cartilage, whereas localization in other tissues and at the joint margins was unaltered. This differed in AIA where increased meniscal staining for S100A8 and S100A9 was observed in association with positive articular chondrocyte staining. This suggests that local factors such as mechanical overloading of the cartilage, rather than humoral agents affecting the whole joint such as cytokines or growth factors, play a significant role in regulating the metabolism of these proteins in cartilage in OA.

MMP-2 and MMP-9 have been shown to degrade S100A8 and S100A9 [31] and both of these MMPs are upregulated in OA cartilage [32,33] and could potentially explain the loss of immunostaining in the mouse model. It is also possible that the increased chondrocyte S100a 8 and S100a9 mRNA in early MMD-induced OA was not translated into protein, through micro-RNA silencing pathways predicted to act on the mRNA of both genes $[34,35]$. However, we speculate that the loss of chondrocyte immunostaining for both S100A8 and S100A9 in early OA while mRNA expression for both proteins is increased, may be due to their secretion from the cell. S100A8 and S100A9 are released from macrophages and neutrophils during inflammation [6], and this secretion is concomitant with loss of cellular immunostaining [36], similar to that observed in the chondrocytes in the present study. S100A9 is released from IL1 -stimulated mouse cartilage in vitro, while S100A8 is not detected in this same conditioned media, suggesting either differential release or extracellular processing/ degradation of the two proteins [37]. In the current study there was evidence of extracellular release of
S100A9, and to a lesser extent S100A8, with positive immunostaining in the surface matrix lamina of IL-1-stimulated mouse femoral head cartilage (Figure 5b). However, the chondrocytes still remained strongly immunopositive for both S100A8 and S100A9 in this IL-1-stimulated cartilage despite secretion of the S100 proteins, which contrasts with lack of chondrocyte staining in OA mouse joints. To date, we have not been able to confirm if there is increased soluble S100A8 or S100A9 in articular cartilage in OA. It remains unclear, therefore, whether release of S100A9 and/or S100A8 from chondrocytes occurs in early OA or with excessive mechanical loading of cartilage.

Release of S100A8 and S100A9 proteins from chondrocytes into the extracellular space, would facilitate their activity as cytokine-like molecules in early OA. We showed that exogenous/extracellular S100A8, and for the first time S100A9 homodimer, could have a role in initiating cartilage degradation by decreasing chondrocyte expression of aggrecan (Acan) and collagen II (Col2a1), but increasing Adamts1, Adamts4, Adamts5, Mmp1, Mmp3, and Mmp13 mRNA levels. The increase in metalloproteinase mRNA was not balanced by a similar increase in TIMPs, promoting a potential imbalance in enzyme/inhibitor ratios and matrix degradation once the pro-MMPs are activated. This is consistent with the recent report showing increased aggrecanolysis in murine patella explant cultures stimulated with S100A8 [9]. The effects of S100A8 on primary ovine articular chondrocytes were in general agreement with that reported in the synovium and macrophages [12], and the $\mathrm{H} 4$ murine chondrocyte cell line [9], although some subtle differences were noted. We found no regulation of Mmp14 by S100A8 in chondrocytes, whereas this enzyme was upregulated in synovium [12]. It has been suggested that the chondroprotection in inflammatory arthritis in S100A9 knock-out mice could be due to the concomitant lack of S100A8 in these animals [9]. Our results have now shown that S100A9 homodimer itself could play a role in cartilage breakdown by inducing similar regulation of potential cartilage-degrading enzymes in chondrocytes as S100A8.

Thus far there is no explanation as to why the heterodimer is inactive and the homodimers are active in chondrocytes. We speculate that the heterodimers may require a trigger for activation in contrast to the homodimers, which are constitutively active. For the murine heterodimer one such trigger is LPS, and activation of cells by LPS is amplified in the presence of the murine heterodimer [11]. It has been suggested that S100A8/ S100A9 complex formation results in conformational change and altered biological function of the individual proteins $[11,38]$. Oligomerization of the heterodimer with calcium/zinc binding may result in steric masking 
of the receptor-binding epitope [38]. This is consistent with the fact that S100A8/S100A9 complex failed to regulate gene expression in chondrocytes. Previously, however, the heterodimercomplex but neither homodimer was found to be active in stimulating endothelial cells [39], and the complex upregulated MMP13 in macrophages to a similar level as the S100A8 homodimer [12]. These divergent results suggest that the $\mathrm{S} 100$ proteins may elicit distinct effects in different cell types within the joint. It would be interesting in the future to determine whether these differential effects are driven by variation in expression of potential receptors for these S100 proteins, such as cell-surface heparan sulfate proteoglycans [40] or toll-like receptor-4 (TLR4) [11], which are expressed by chondrocytes [41,42]. TLR4 in particular has been strongly implicated in joint inflammation and cartilage destruction in experimental inflammatory arthropathies in mice [43].

\section{Conclusions}

We have shown that extracellular S100A8 and S100A9 homodimers can both stimulate a degradative response in articular chondrocytes. Dysregulation of the synthesis and release of these two proteins by chondrocytes could play a role in cartilage destruction in arthritis. However, our studies comparing surgically-induced OA with AIA in mice, suggests that although S100A8 and S100A9 may have a role in initiating early cartilage degradation in both arthropathies, they are unlikely to have a significant role in the ongoing cartilage degradation in chronic/late-stage OA. Defining the differences in pathophysiological pathways and mechanisms in different arthritic conditions and in different stages of disease is important in designing better therapies.

\footnotetext{
Additional file 1: Excel file containing the raw microarray data from the Agilent $44 \mathrm{~K}$ arrays comparing the expression of S100 proteins in microdissected non-calcified articular cartilage pooled from three separate animals one, two and six weeks after medial meniscal destabilization or sham surgery.

Click here for file

[http://www.biomedcentral.com/content/supplementary/ar2917-S1.xls ]

Additional file 2: Excel file containing the raw microarray data from the Agilent $44 \mathrm{~K}$ arrays comparing the expression of S100 proteins in femoral head cartilage pooled from three separate cultures under control and IL1-stimulated conditions for two and four day.

Click here for file

[http://www.biomedcentral.com/content/supplementary/ar2917-S2.xls ]
}

\section{Acknowledgements}

This study was supported by grants from the Australian Research Council, the National Health \& Medical Research Council (NHMRC) of Australia and the Ulysses Club. The authors thank Colin Dunstan (funded by the University of Sydney), and Ms Susan Smith (funded by Royal North Shore Hospital) for their assistance. We thank Su Yim Lim (funded by NHMRC) for S100 proteins supplied in the early phase of this project. We are grateful to Carolyn Geczy (funded by NHMRC) for the anti-S100 antibodies, and contributions to the manuscript.

\section{Author details}

${ }^{1}$ Tissue Engineering and Biomaterials Research Unit, School of AMME J07, Faculty of Engineering, Bosch Institute, University of Sydney, Corner of Shepherd and Cleavland Street, New South Wales 2006, Australia. ${ }^{2}$ Murdoch Childrens Research Institute and the Department of Paediatrics, University of Melbourne, Royal Children's Hospital, Flemmington Road, Parkville, Victoria 3052, Australia. ${ }^{3}$ Raymond Purves Bone and Joint Research Laboratories, Kolling Institute of Medical Research, University of Sydney at Royal North Shore Hospital, Reserve Road, St. Leonards, New South Wales 2065, Australia. ${ }^{4}$ Institute of Immunology, University Hospital of Muenster, Roentgenstrasse 21, D-48149 Muenster, Germany.

\section{Authors' contributions}

$\mathrm{HZ}$ contributed to study design, acquisition of data, analysis and interpretation of data, and manuscript preparation. DB contributed to acquisition of data, analysis and interpretation of data, and manuscript preparation. MMS contributed to acquisition of data, analysis and interpretation of data, manuscript preparation, and statistical analysis. RW contributed to acquisition of data. LAR contributed to acquisition of data, and manuscript preparation. $\mathrm{KJ}$ contributed to analysis and interpretation of data. YR contributed to analysis and interpretation of data, and manuscript preparation. TV contributed to analysis and interpretation of data, and manuscript preparation. JR contributed to manuscript preparation. JFB contributed to manuscript preparation. CBL contributed to study design, acquisition of data, analysis and interpretation of data, manuscript preparation, animal management, and animal surgery. All authors read and approved the final manuscript.

\section{Competing interests}

The authors declare that they have no competing interests.

Received: 3 August 2009 Revisions requested: 24 September 2009 Revised: 18 November 2009 Accepted: 27 January 2010

Published: 27 January 2010

\section{References}

1. Vogl T, Ludwig S, Goebeler M, Strey A, Thorey IS, Reichelt R, Foell D, Gerke V, Manitz MP, Nacken W, Werner S, Sorg C, Roth J: MRP8 and MRP14 control microtubule reorganization during transendothelial migration of phagocytes. Blood 2004, 104:4260-4268.

2. Cornish CJ, Devery JM, Poronnik P, Lackmann M, Cook DI, Geczy CL: S100 protein CP-10 stimulates myeloid cell chemotaxis without activation. J Cell Physiol 1996, 166:427-437.

3. Harrison CA, Raftery MJ, Walsh J, Alewood P, lismaa SE, Thliveris S, Geczy CL: Oxidation regulates the inflammatory properties of the murine S100 protein S100A8. J Biol Chem 1999, 274:8561-8569.

4. Raftery MJ, Collinson L, Geczy CL: Overexpression, oxidative refolding, and zinc binding of recombinant forms of the murine S100 protein MRP14 (S100A9). Protein Expr Purif 1999, 15:228-235.

5. Cecil DL, Johnson K, Rediske J, Lotz M, Schmidt AM, Terkeltaub R: Inflammation-induced chondrocyte hypertrophy is driven by receptor for advanced glycation end products. J Immunol 2005, 175:8296-8302.

6. Manitz MP, Horst B, Seeliger S, Strey A, Skryabin BV, Gunzer M, Frings W, Schonlau F, Roth J, Sorg C, Nacken W: Loss of S100A9 (MRP14) results in reduced interleukin-8-induced $C D 11 \mathrm{~b}$ surface expression, a polarized microfilament system, and diminished responsiveness to chemoattractants in vitro. Mol Cell Biol 2003, 23:1034-1043.

7. Odink K, Cerletti N, Bruggen J, Clerc RG, Tarcsay L, Zwadlo G, Gerhards G, Schlegel $R$, Sorg C: Two calcium-binding proteins in infiltrate macrophages of rheumatoid arthritis. Nature 1987, 330:80-82. 
8. Roth J, Teigelkamp S, Wilke M, Grun L, Tummler B, Sorg C: Complex pattern of the myelo-monocytic differentiation antigens MRP8 and MRP14 during chronic airway inflammation. Immunobiology 1992, 186:304-314.

9. van Lent $\mathrm{PL}$, Grevers $L C$, Blom AB, Arntz OJ, Loo van de FA, Kraan van der P, Abdollahi-Roodsaz S, Srikrishna G, Freeze H, Sloetjes A, Nacken W, Vogl T, Roth J, Berg van den WB: Stimulation of chondrocyte-mediated cartilage destruction by S100A8 in experimental murine arthritis. Arthritis Rheum 2008, 58:3776-3787.

10. Youssef P, Roth J, Frosch M, Costello P, Fitzgerald O, Sorg C, Bresnihan B: Expression of myeloid related proteins (MRP) 8 and 14 and the MRP8/14 heterodimer in rheumatoid arthritis synovial membrane. J Rheumatol 1999, 26:2523-2528.

11. Vogl T, Tenbrock K, Ludwig S, Leukert N, Ehrhardt C, van Zoelen MA, Nacken W, Foell D, Poll van der T, Sorg C, Roth J: Mrp8 and Mrp14 are endogenous activators of Toll-like receptor 4, promoting lethal, endotoxin-induced shock. Nat Med 2007, 13:1042-1049.

12. van Lent $P L$, Grevers $L$, Blom AB, Sloetjes A, Mort JS, Vogl T, Nacken W, Berg van den WB, Roth J: Myeloid-related proteins S100A8/S100A9 regulate joint inflammation and cartilage destruction during antigeninduced arthritis. Ann Rheum Dis 2008, 67:1750-1758.

13. Zreiqat H, Howlett CR, Gronthos S, Hume D, Geczy CL: S100A8/S100A9 and their association with cartilage and bone. J Mol Histol 2007, 38:381-391.

14. Barksby HE, Hui W, Wappler I, Peters HH, Milner JM, Richards CD, Cawston TE, Rowan AD: Interleukin-1 in combination with oncostatin M up-regulates multiple genes in chondrocytes: implications for cartilage destruction and repair. Arthritis Rheum 2006, 54:540-550.

15. Kobayashi M, Squires GR, Mousa A, Tanzer M, Zukor DJ, Antoniou J, Feige U, Poole AR: Role of interleukin-1 and tumor necrosis factor alpha in matrix degradation of human osteoarthritic cartilage. Arthritis Rheum 2005, 52:128-135.

16. Little CB, Meeker CT, Golub SB, Lawlor KE, Farmer PJ, Smith SM, Fosang AJ: Blocking aggrecanase cleavage in the aggrecan interglobular domain abrogates cartilage erosion and promotes cartilage repair. J Clin Invest 2007, 117:1627-1636.

17. Little CB, Mittaz L, Belluoccio D, Rogerson FM, Campbell IK, Meeker CT, Bateman JF, Pritchard MA, Fosang AJ: ADAMTS-1-knockout mice do not exhibit abnormalities in aggrecan turnover in vitro or in vivo. Arthritis Rheum 2005, 52:1461-1472.

18. Melrose J, Smith S, Ghosh P: Assessment of the cellular heterogeneity of the ovine intervertebral disc: comparison with synovial fibroblasts and articular chondrocytes. Eur Spine J 2003, 12:57-65.

19. Vogl T, Leukert N, Barczyk K, Strupat K, Roth J: Biophysical characterization of S100A8 and S100A9 in the absence and presence of bivalent cations. Biochim Biophys Acta 2006, 1763:1298-1306.

20. Vogl T, Roth J, Sorg C, Hillenkamp F, Strupat K: Calcium-induced noncovalently linked tetramers of MRP8 and MRP14 detected by ultraviolet matrix-assisted laser desorption/ionization mass spectrometry. J Am Soc Mass Spectrom 1999, 10:1124-1130.

21. Smith MM, Sakurai G, Smith SM, Young AA, Melrose J, Stewart CM, Appleyard RC, Peterson JL, Gillies RM, Dart AJ, Sonnabend DH, Little CB: Modulation of aggrecan and ADAMTS expression in ovine tendinopathy induced by altered strain. Arthritis Rheum 2008, 58:1055-1066.

22. Bustin SA: Quantification of mRNA using real-time reverse transcription PCR (RT-PCR): trends and problems. J Mol Endocrinol 2002, 29:23-39.

23. Smyth GK, Speed T: Normalization of cDNA microarray data. Methods 2003, 31:265-273.

24. Wettenhall JM, Smyth GK: limmaGUI: a graphical user interface for linear modeling of microarray data. Bioinformatics 2004, 20:3705-3706.

25. Belluoccio D, Bernardo BC, Rowley L, Bateman JF: A microarray approach for comparative expression profiling of the discrete maturation zones of mouse growth plate cartilage. Biochim Biophys Acta 2008, 1779(5):330-340.

26. Campos-Xavier AB, Martinet D, Bateman J, Belluoccio D, Rowley L, Tan TY, Baxova A, Gustavson KH, Borochowitz ZU, Innes AM, Unger S, Beckmann JS, Mittaz L, Ballhausen D, Superti-Furga A, Savarirayan R, Bonafe L: Mutations in the heparan-sulfate proteoglycan glypican 6 (GPC6) impair endochondral ossification and cause recessive omodysplasia. Am J Hum Genet 2009, 84:760-770.

27. Vandesompele J, De Preter K, Pattyn F, Poppe B, Van Roy N, De Paepe A, Speleman F: Accurate normalization of real-time quantitative RT-PCR data by geometric averaging of multiple internal control genes. Genome Biol 2002, 3:RESEARCH0034.

28. lismaa SE, Hu S, Kocher M, Lackmann M, Harrison CA, Thliveris S, Geczy CL: Recombinant and cellular expression of the murine chemotactic protein, CP-10. DNA Cell Biol 1994, 13:183-192.

29. Roth J, Burwinkel F, Bos van den C, Goebeler M, Vollmer E, Sorg C: MRP8 and MRP14, S-100-like proteins associated with myeloid differentiation, are translocated to plasma membrane and intermediate filaments in a calcium-dependent manner. Blood 1993, 82:1875-1883.

30. Benjamini Y: Controlling the false discovery rate: a practical and powerful approach to multiple testing. Journal of the Royal Statistical Society Series 1995, 57:289-300.

31. Greenlee K, Corry DB, Engler DA, Matsunami RK, Tessier P, Cook RG, Werb Z, Kheradmand F: Proteomic identification of in vivo substrates for matrix metalloproteinases 2 and 9 reveals a mechanism for resolution of inflammation. J Immunol 2006, 177:7312-7321.

32. Davidson RK, Waters JG, Kevorkian L, Darrah C, Cooper A, Donell ST, Clark IM: Expression profiling of metalloproteinases and their inhibitors in synovium and cartilage. Arthritis Res Ther 2006, 8:R124.

33. Wu J, Liu W, Bemis A, Wang E, Qiu Y, Morris EA, Flannery CR, Yang Z: Comparative proteomic characterization of articular cartilage tissue from normal donors and patients with osteoarthritis. Arthritis Rheum 2007, 56:3675-3684.

34. Li Z, Luo RT, Mi S, Sun M, Chen P, Bao J, Neilly MB, Jayathilaka N, Johnson DS, Wang L, Lavau C, Zhang Y, Tseng C, Zhang X, Wang J, Yu J, Yang H, Wang SM, Rowley JD, Chen J, Thirman MJ: Consistent deregulation of gene expression between human and murine MLL rearrangement leukemias. Cancer Res 2009, 69:1109-1116.

35. Maru DM, Singh RR, Hannah C, Albarracin CT, Li YX, Abraham R, Romans AM, Yao H, Luthra MG, Anandasabapathy S, Swisher SG, Hofstetter WL, Rashid A, Luthra R: MicroRNA-196a is a potential marker of progression during Barrett's metaplasia-dysplasia-invasive adenocarcinoma sequence in esophagus. Am J Pathol 2009, 174:1940-1948.

36. Kumar RK, Yang Z, Bilson S, Thliveris S, Cooke BE, Geczy CL: Dimeric S100A8 in human neutrophils is diminished after phagocytosis. J Leukoc Biol 2001, 70:59-64.

37. Wilson R, Belluoccio D, Little CB, Fosang AJ, Bateman JF: Proteomic characterization of mouse cartilage degradation in vitro. Arthritis Rheum 2008, 58:3120-3131.

38. Leukert N, Vogl T, Strupat K, Reichelt R, Sorg C, Roth J: Calcium-dependent tetramer formation of S100A8 and S100A9 is essential for biological activity. J Mol Biol 2006, 359:961-972.

39. Ehlermann P, Eggers K, Bierhaus A, Most P, Weichenhan D, Greten J, Nawroth PP, Katus HA, Remppis A: Increased proinflammatory endothelial response to $\mathrm{S} 100 \mathrm{~A} 8 / \mathrm{A} 9$ after preactivation through advanced glycation end products. Cardiovasc Diabetol 2006, 5:6.

40. Robinson MJ, Tessier P, Poulsom R, Hogg N: The S100 family heterodimer, MRP-8/14, binds with high affinity to heparin and heparan sulfate glycosaminoglycans on endothelial cells. J Biol Chem 2002, 277:3658-3665.

41. Bobacz K, Sunk IG, Hofstaetter JG, Amoyo L, Toma CD, Akira S, Weichhart T, Saemann M, Smolen JS: Toll-like receptors and chondrocytes: the lipopolysaccharide-induced decrease in cartilage matrix synthesis is dependent on the presence of toll-like receptor 4 and antagonized by bone morphogenetic protein 7. Arthritis Rheum 2007, 56:1880-1893.

42. Farach-Carson MC, Hecht JT, Carson DD: Heparan sulfate proteoglycans: key players in cartilage biology. Crit Rev Eukaryot Gene Expr 2005, 15:29-48.

43. van Lent PL, Blom AB, Grevers L, Sloetjes A, Berg van den WB: Toll-like receptor 4 induced FcgammaR expression potentiates early onset of joint inflammation and cartilage destruction during immune complex arthritis: Toll-like receptor 4 largely regulates FcgammaR expression by interleukin 10. Ann Rheum Dis 2007, 66:334-340.

44. Lee JH, Fitzgerald JB, Dimicco MA, Grodzinsky AJ: Mechanical injury of cartilage explants causes specific time-dependent changes in chondrocyte gene expression. Arthritis Rheum 2005, 52:2386-2395.

doi:10.1186/ar2917

Cite this article as: Zreiqat et al:: S100A8 and S100A9 in experimental osteoarthritis. Arthritis Research \& Therapy 2010 12:R16. 